\title{
Are the East Asian Economies Decoupling? Empirical Evidence and Rhetorical Reasoning
}

\author{
WERNER PASCHA AND JIHEE YOON
}

\begin{abstract}
In this article, the authors look at the decoupling debate with respect to East Asia from an economic and a political economy perspective. Looking at various methods, they find little evidence to support a secular decoupling hypothesis, that is, the proposition that there is a long-term trend towards a decoupling of the East Asian region. In this context, they present fresh evidence on GDP data up to the second quarter of 2009, incorporating some of the impact of the recent financial crisis. They find evidence in favour of a cyclical relationship: decoupling during economic upturns and re-coupling during downturns. They also look at the sources for the strong interest in the concept, drawing some parallels to the older concept of the flying geese pattern of development. Key factors are the activity of financial analysts and the interest of some policy circles in the region to support calls for further regional integration with putative empirical evidence. The debate on decoupling captures some interesting points about the peculiar political and economic exchange on the regional level. Nevertheless, the authors conclude that seemingly detached economic reasoning is often subject to over- and even misinterpretation and should be accompanied by more political economy-based reasoning on the discursive patterns of the debate.
\end{abstract}

Keywords: decoupling, East Asia, regional integration, financial crisis, business cycles

\section{Introduction}

In recent years, East Asia has become a cornerstone of the global economy due to the phenomenal growth of its gross domestic product (GDP) and of its outward-oriented trade activities. A major engine of this growth has been the external final demand created in the Western world, by the US and Western Europe in particular. More recently, however, it has been asked whether the East Asian economies have begun to decouple from final demand in the West and have thus started to develop their indigenous growth dynamics. Following the global financial and economic crisis, it has also been asked to what extent such trends persist. 
A positive answer might have considerable implications for trade and industrial policies of the regional economies. Identifying decoupling could serve as a powerful argument to support a regionalist integration strategy, while denying any evidence of decoupling could strengthen the case for continued multilateralism. Some interpretations of recent evidence may thus have been influenced by wishful thinking - or even by deliberate one-sidedness.

For some years during the mid-noughties, decoupling became a popular concept in parts of the learned literature. For instance, in Google Scholar, the use of 'decoupling', 'economic' and 'Asia' has risen from below 1,000 hits in 2003 to 1,470 in 2009. Interest seems to have declined somewhat during the global financial crisis, at least based on internet searches according to Google Insights for Search.

With this background, this article discusses the relationship between objective empirical evidence and subjective rhetorical patterns, that is, how evidence is utilized to support analytical conjectures or to tell stories of recent developments. A major point will be to demonstrate how difficult it is to find robust evidence for or against decoupling. In this context, we will also present some fresh evidence on the possible decoupling of East Asia. Instead of pursuing the established way of using trade data to identify any degree of decoupling, we take the more unusual route, to work with GDP data. We do this because of the strong supply-chain linkages among East Asian economies that create many intraregional, intermediate good trade flows, but 'hide' the true extent of external dependence of East Asian economic performance. Moreover, there is reason to believe that tendencies of coupling or decoupling are related to periods of global crisis or external shocks. With respect to the recent past, some argue that the end of the 'sunshine period' of the global economy, namely the global economic crisis that seems to have culminated in the closure of Lehman Brothers in September 2008, has meant an end for any decoupling of East Asia, and that strong East Asian exporters such as Japan and South Korea have been even more vulnerable to shrinking global demand than many Western economies. However, it has also been said that the strong recovery of export-oriented economies like South Korea, or the successful Chinese recovery program that has helped the whole region, actually provide evidence of a swift return of decoupling (e.g., Oakley 2009). We therefore include recent GDP data in our analysis and look for changing decoupling trends before and during the crisis.

The rest of the article is organized as follows: first, we present a short overview of major strands of the available literature on the decoupling 
of East Asia and argue that the evidence is mixed and inconclusive. We will look into different data sources and analytical methods used to see why. Second, we introduce our own approach, using GDP data to look at decoupling phenomena. Namely, we follow Fidrmuc and Korhonen (2009) to look at the international correlation of business cycles by identifying and interpreting moving correlations among selected Asian economies with regional and extra-regional economies. We will present our data and calculations, not because we consider this analysis necessarily superior, although we consider the use of GDP data to be less problematic than to rely on trade data, but to demonstrate the subtle difficulties in interpreting results properly. Third, we will discuss why the debate of decoupling should rather be seen as a political-economic phenomenon, in which interests play a major role. As such, this debate presents interesting similarities to the earlier debate of a flying geese pattern of economic development in East Asia. We conclude that the economic analysis of regional economic relations of East Asia should involve more works that incorporate a political-economic dimension. While leading think-tanks in the region and those that study the region mostly employ a narrow economic perspective, they should widen their agenda to incorporate the broader concerns of political economy.

\section{The Decoupling of East Asia: Available Empirical Evidence}

The basic problem with respect to identifying evidence for (or against) the decoupling thesis is that the very term decoupling is not strictly defined. It has no foundation in economic theory, and in that respect it is similar to a loose term like 'competitiveness'. If one defines competitiveness as the sustainable ability of an entity to compete profitably on world markets, it is quite open which variables can signal such a lasting ability. Moreover, although one frequently speaks of the competitiveness of a nation, it can indeed be questioned whether it is meaningful to designate countries as (un)competitive, as Krugman (1994) has emphatically argued. For decoupling, the void of a theoretical foundation can be perceived when noting that economic theory does not allow a clear prediction whether more economic integration through trade and other activities should lead to coupling or, indeed, decoupling of economic areas (see Kim, Lee \& Park 2009: 3, and the literature quoted there); growing trade interdependence could be considered to cause more spillovers, for instance in terms of aggregate demand, technology 
spillovers or the effects of price changes. This would imply a stronger co-movement of economies, that is to say, coupling. However, economic integration may also increase specialization, as the opening of countries towards the world economy forces them to concentrate on their respective competitive advantages, which are necessarily different from those of other countries. This would imply less co-fluctuation among economies. Finally, it is also conceivable that the outcome depends on certain structural characteristics: for instance, when intra-industry trade is dominating between two economies, one might expect a high positive correlation among them, as their co-movement is shaped by similar factors; for a dominance of inter-industry trade, the opposite may be expected.

Decoupling can also mean different things to different observers. Starting from a 'rough and dirty' definition that (de)coupling is about whether the linkages between two areas (such as world regions or national economies) deepen or loosen, the first issue is which kind of interactive variables should be considered as appropriate proxies for a (de)coupling of economic areas. One may first want to distinguish real and financial economic interactions. In a wider sense, other flows also may be considered, such as labour migration, the number of exchange students, tourism, translations of books, film showings, etc.

Financial market-related data is often used to discuss (de)coupling in the East Asian region, originating from the interest in investment opportunities, but also from the perspective of conditions for further market or institutional integration in the financial/monetary sphere. With respect to financial flows between various Asian economies, portfolio flows within the region have been increasing, but they are still quite low compared to interregional activities. Nevertheless, major financial prices, such as interest rates, bond yields and stock market valuations, have been converging in recent years (Kawai 2009: 4). While this is important news for investors or for policymakers interested in financial market structure, it is much less clear what this means for (de)coupling in a more limited sense. Financial market integration or coupling is neither a necessary nor a sufficient condition for real market integration or coupling. It is not necessary, because real economic activities can function as a substitute for rather closed financial markets that are hardly integrated. Nor is it sufficient, because while one would expect financial price alignment in strongly integrated financial markets, this may be compatible with very divergent production structures and relationships. 
There is no obvious theory-based argument whether, in the narrower context, real or financial transactions should be more important for (de)coupling. It is tempting to argue that real variables better cover the concept that economic regions are possibly linked through their peculiar production structures and the resulting flow of goods. From that perspective, trade and investment flows are the prime candidates to examine to study decoupling. However, real economic structures may also be considered as a manifestation of more underlying financial variables, such as the propensities to save and invest. Financial marketrelated variables like the intensity of capital transfers, the synchronicity of exchange rate movements and interest rates or the co-movement of stock market evaluations would be phenomena to look for.

On a different level, the concept of (de)coupling always implies a comparison of an in-group with an out-group, for instance the relations among the Northeast Asian economies in comparison to their relations with Western advanced economies. This is more complex than may seem at first sight. In the literature on the intensity of regional interdependence in Pacific Asia, this has been well studied. Several authors and the public media have noted the growing trade flows between Asian economies for a long time. However, a growing volume of trade between two economies, A and B, may simply be due to the fact that A's propensity to trade with the rest of the world is increasing and/or that B's propensity is increasing, or indeed that world trade is growing and $\mathrm{A}$ as well as B are simply following this trend. Compared to noting the change of trade volumes between A and B over time at face value, one should thus at least quote it in relation to the development of total world trade; this ratio is often called the absolute measure of trade intensity. In the relative measure of trade intensity, this value is related to either the overall export propensity of the exporting entity A or to the overall import propensity of the importing entity B. In case of the double-relative trade intensity measure, both scaling factors are applied. The consequences of using these concepts can be quite surprising. According to a quantitative analysis by Urata (2004), the absolute trade intensity of East Asia increased from 5.4 per cent to 11.3 per cent between 1980 and 1999. That means that East Asia's share of intra-regional trade among world trade almost doubled. However, the trade intensity index according to the double-relative measure actually declined from 2.56 to 2.25 during the same period. In other words, it is true that East Asian economies intensively trade with each other; this is signalled by a value of greater than 1 . Actually, the trade intensity is 
more than twice the level that one would expect, on the background of the general export and import propensities of the regional economies. However, this (double-relative) intensity has not risen further between 1980 and 1999; the impressive growth of intra-regional trade is simply due to the considerable outward orientation of East Asian economies, irrespective of regional or extra-regional trading partners. Urata's conclusions, which also hold for direct foreign investment relations as may be noted in passing, are in line with earlier studies using a similar methodology. For instance, in an early study of this type, Frankel (1997; based on his earlier papers) noted a U-shaped trend curve of East Asian intra-regional trade intensity in recent decades, with the rise in the later post-war period reflecting a rebound of regional trade links that were cut through the Pacific War. He was dubious whether the trend would continue. For our topic at hand, it is noteworthy that operational specifications of (de)coupling can be very sensitive with respect to the methodology employed to cover 'intensity'.

Methodological issues can get much more complex. Let us consider the most straightforward way to discuss (de)coupling further, namely with respect to international trade in terms of some of the methodological issues involved. A major problem with trade figures is that they encompass both finished and intermediate goods (apart from services). Particularly, intermediate goods are not necessarily meant for the market of the country into which they are imported, but they may be used up in production processes and may eventually end up as exports headed for final consumption in a third-country market, possibly outside of the region. The difference between the two types of goods can be quite significant. According to UN trade data collected by Pula and Peltonen (2009), the volume of intra-regional exports of final goods within East Asia actually declined from 2.0 per cent of regional GDP in 1998 to 1.7 per cent in 2006, while intermediate goods exports rose significantly from 8.9 per cent to 14.8 per cent of GDP (see Table 1 ). In other words, insofar as the intra-regional growth of trade in goods grew stronger than GDP during the reporting period, this was entirely due to the rise of trade in intermediate goods, which are particularly suspect as they eventually may be heading for third-country markets. Thus, simply pointing out the strong growth of intra-regional trade is far from sufficient.

A way out of this problem is offered by input-output analysis. An input-output (IO) table supplies information on the structure of relationships. Normally, IO tables are set up for domestic economies, differentiating between different industries and showing to what extent 
TABLE 1: Final and Intermediate Good Exports in East Asian Trade

\begin{tabular}{|l|c|c|c|c|c|c|}
\hline \multirow{2}{*}{} & \multicolumn{7}{|c|}{ in per cent of GDP } \\
\cline { 2 - 7 } & \multicolumn{2}{|c|}{ Total } & \multicolumn{2}{c|}{ Final } & \multicolumn{2}{c|}{ Intermediate } \\
\cline { 2 - 7 } & 1998 & 2006 & 1998 & 2006 & 1998 & 2006 \\
\hline $\begin{array}{l}\text { Export to G3 countries (US, } \\
\text { EU-15, Japan) }\end{array}$ & 16.2 & 18.7 & 6.4 & 6.0 & 9.8 & 12.7 \\
\hline within that to US & 7.3 & 7.8 & 3.2 & 2.9 & 4.2 & 4.9 \\
\hline to the EU & 5.1 & 6.7 & 1.8 & 2.0 & 3.4 & 4.8 \\
\hline to Japan & 3.7 & 4.1 & 1.5 & 1.1 & 2.3 & 3.0 \\
\hline Intra-regional exports & 11.0 & 16.5 & 2.0 & 1.7 & 8.9 & 14.8 \\
\hline \multicolumn{1}{|c|}{ within that to China } & 6.2 & 12.1 & 0.8 & 0.6 & 5.5 & 11.5 \\
\hline Rest of the World & 7.2 & 10.2 & 2.1 & 2.5 & 5.1 & 7.7 \\
\hline Total exports of goods & 34.4 & 45.3 & 10.5 & 10.2 & 23.8 & 35.1 \\
\hline Memo item & & & & & & \\
\hline Exports, goods and services & 42.8 & 53.4 & & & & \\
\hline
\end{tabular}

inputs, including products from various industries, are used for the production of outputs, including industry-specific output. In the case of international IO tables, the relationship matrix consists of imports from one country used up in the exports of another country. For the Asia-Pacific area, Japan's Institute for Developing Economies (IDE) has prepared such an international IO table for the years 1985, 1990, 1995, and 2000. Generally speaking, international IO analysis allows for interesting results. For instance, one can calculate backward linkages through the IO relations, that is, asking which production in regional production is necessary to allow for production elsewhere when interlinkages are considered. One can also extend this analysis and ask to what extent demand in a certain country - intermediate and final demand -creates value added through the production of utilized goods elsewhere, in a supply country. This is extremely helpful for the question of decoupling: to what extent, for instance, will increased demand in China create production and eventually value added in other Asian countries? Pula and Peltonen (2009) make use of IDE's IO table and study to what extent demand in one country creates value added elsewhere, to answer the question whether value added in Pacific Asia is driven by domestic, by intra- or by extra-regional demand. In a nutshell, the authors find that supply sources within the region are still concentrated over the years 1995, 2000, and 2006, but China has started to occupy a more important role than Japan. With respect to value-added generation, the role of domestic final demand has declined, but its share has been taken up by extra-regional demand (coupling) rather than intra-regional demand (pp. 22-24); reliance on trade for value-added creation is significantly 
less than suggested by face-value trade data. All these insights make this approach of looking behind the superficial and - because of interlinkages - bloated trade data ('bubble trade') particularly valuable.

Why is this approach so rare, then, although it can be considered one of the few available that treats the problem of structural interrelationships of trade properly? One issue is that the effort necessary to prepare such a table is considerable. This is the reason why the latest Asian IO table is from 2000 (the 2005 table is expected to be made public in mid-2011). Timely information, for instance covering the impact or responses to the global financial crisis, thus cannot be expected. Pula and Peltonen (2009) try to tackle this hurdle by updating the Asian IO table at least to 2006. Basically (for details, see their appendix 2), they use reported import data to update the cells of the trade matrix between the various countries, taking change towards intermediate goods trade into consideration. While testing for plausibility, of course this procedure can only be second best, because potential structural changes cannot be adequately covered. Another limitation of the IO approach is that it is restricted to the 'mechanics' of the trade relationship. For instance, for the individual cells of the matrix, which contain information on imports from one country used for the production activities of another country, it is assumed that these relationships are fixed for the time being, without substitutability, irrespective of price changes or anything else. This also implies that only the 'direct' trade effects are considered, while the implications of wider macroeconomic linkages such as employment changes or financial market interactions are not covered.

A very basic alternative to utilizing trade data is to study the potential role of (de)coupling through GDP data. In a way, all the potential macro and micro effects of economic interlinkages, including financial market interaction, are eventually covered in the (co-)movement of GDP. This is a major advantage of using it in comparison to trade-related approaches. Some definitions of decoupling are actually geared towards such an understanding. For instance, the Asian Development Bank (ADB) defines decoupling as 'the emergence of a business cycle dynamic that is relatively independent of global demand trends and that is driven mainly by autonomous changes in internal demand'. With this definition, it is understood that GDP will always show some movement due to business cycle phenomena. From this perspective, (de)coupling can never be deduced from the raw data of GDP co-movement. Rather, the effects of business cycle co-movement, also in relation to other world regions, have to be statistically eliminated one way or another. How to 
do this obviously creates a considerable number of questions and leads to potentially divergent results. In the following section, we will use this approach to illustrate some of these issues.

\section{Illustrating an Empirical Approach: Model, Data and Results}

To discuss the issue of analyzing phenomena of (de)coupling with GDP data, we start with a conjecture based on the ADB definition of coupling introduced above. If one finds an 'emergence of a business cycle dynamic that is relatively independent of global demand trends and that is driven mainly by autonomous changes in internal demand' (ADB 2007: 66), this would be considered evidence for decoupling as a secular trend beyond business cycles. As a counter-proposition, any observed decoupling could primarily be limited to specific parts of a cycle: decoupling during upturns (and re-coupling during downturns). During upturns, some group of countries may be able to make particularly good use of the benign economic environment, grow strongly and develop ever-stronger links amongst each other, thus effectively decoupling from the development of other economies to some extent. During common downturns, which may originate on the group levellike the Asian financial crisis - or on the global level-like the recent global financial crisis - this group of countries may be subject to strong downward pressure, thus actually re-coupling with the development of other economies to some extent. In the first case, the proposition could be called the secularity thesis of decoupling, in the latter case, the cyclicality thesis, although this does not need to refer to a strictly defined and rigorously identified business cycle.

Inspired by the approach of Fidrmuc and Korhonen (2009), we use GDP data to identify and interpret a correlation of business cycles between various East Asian economies and with major external economies. We have chosen China, Japan, South Korea, Hong Kong and Singapore as regional economies and related them to the US, Germany, France, Italy and the UK as Western advanced economies. We first calculated moving correlations of real GDP growth figures, using nominal GDP and the GDP deflator from the International Financial Statistics of the IMF (see IMF no date). The GDP data used is a de-trended, i.e. seasonally adjusted, quarter-on-quarter real growth rate with a four-year moving window. Put differently, we look at whether the GDP in two countries moves in the same direction - without being able to say which country 
follows the other-or whether the relationship is due to some other country, some other factor or even whether it is purely coincidental. To see such a relationship, the GDP data is pre-arranged in three ways. First, the data is smoothened through averaging; otherwise, the changes seem too erratic. Second, a general growth trend is cut out: if one country is growing, another is shrinking, and this should not be considered when looking for the relationship of fluctuations. Third, inflation (or deflation) is adjusted, as one would be interested in the relationship of the real economies. A second, related approach is a trend analysis of the data, trying to identify whether there have been changes since the early 1990s due to the so-called Asian crisis of 1997-1998 and the global (financial) crisis that started in 2007, with its culmination in September 2008 (Lehman collapse). We do this by accounting for the two crises and the intermediate period, which may have started a move towards decoupling, as dummy variables in a panel regression of the de-trended GDP growth of China and South Korea.

First, we turn to the correlation of GDP growth rates. As these values fluctuate quite widely, we use four-year averages to smoothen them. For an illustration, Table 2 presents a small number of the bilateral pairs under review. To detect coupling and re-coupling as processes, it is important to look at the positive or negative slope of the curves in the following graphs, while it is less important whether the curves are in positive or negative territory. For instance, in the South Korea-US relationship, the reported correlation reached about 0.4 around early 2000 (see Table 2b). Until late 2003, there was still a slightly positive relationship of GDP development between both countries, but the more important message is that this relationship has become weaker, that is, both countries have started to decouple, visualized in a descending graph. For the important US-Japan relationship, only from 2005 to 2008 does one notice a rather strong decoupling, achieved through the comparably strong US growth and the somewhat lukewarm recovery of Japan (Table 2a). During the recent global crisis, however, there was a significant re-coupling. As for South Korea and the US, one also notices some decoupling around the mid-2000s, followed by a strong re-coupling during the crisis. Between China and South Korea (Table 2c), there has been a very strong intra-regional coupling due to the pronounced dependency of South Korea on China's growth in recent years. Finally, for the increasingly important US-China link (Table 2d), there seems to have been no strong trends in recent years; however, since about 2006 there is some re-coupling. 
The small survey already shows that it is quite difficult to reach conclusions on whether there is a persistent tendency of (de)coupling in either direction. Generalizing to some extent, our findings from calculating the co-movements of GDP growth are as follows: broadly speaking, correlations between East Asia and the West are rather low. During the recent crisis, correlations with the West rose significantly, particularly for Japan, but also for others. For China, correlations with the West increased somewhat during the crisis, but from rather low levels. This supports the cyclicality thesis, that is to say, some decoupling during upturn movements, but re-coupling during downturns - not based on strictly defined business cycles, but on the ups and downs around a crisis. Since early 2009, the situation has stabilized somewhat again, the

TABLE 2: Four-Year Moving Averages of Real De-trended GDP Growth Rate Correlation(1995/1Q 2010/4Q) for Selected Country Pairs a. Japan - US

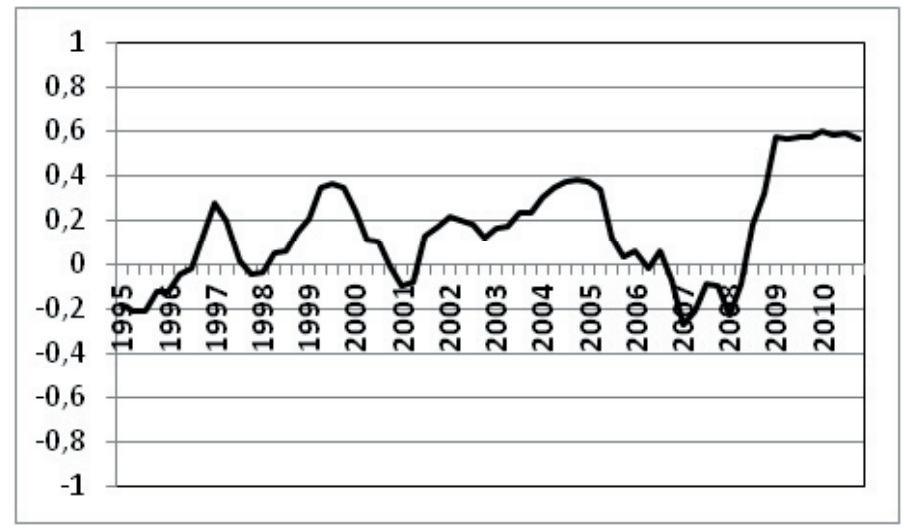

\section{b. South Korea - US}

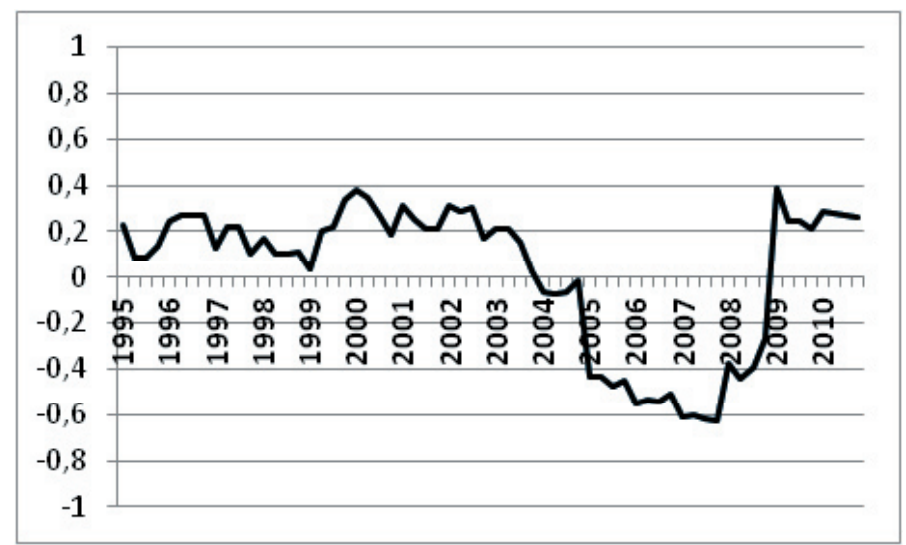




\section{c. China-South Korea}

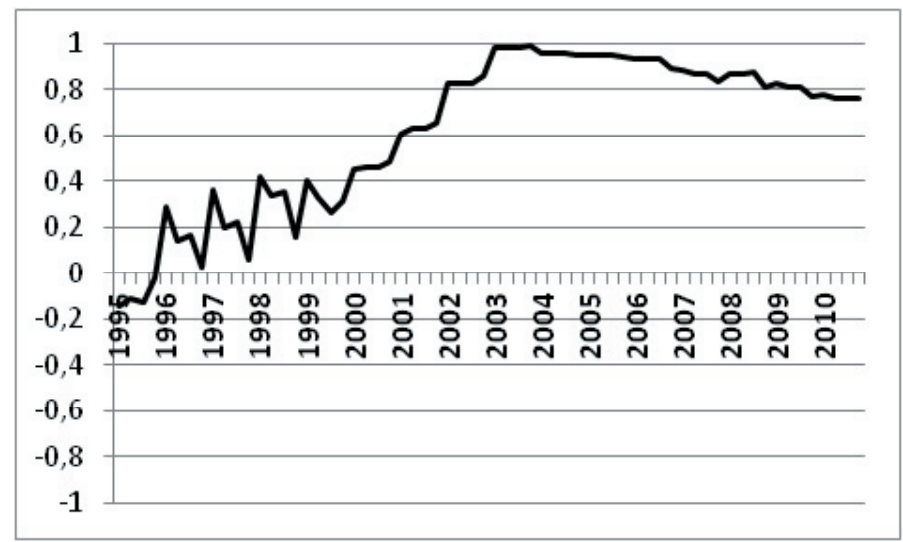

\section{d. China-US}

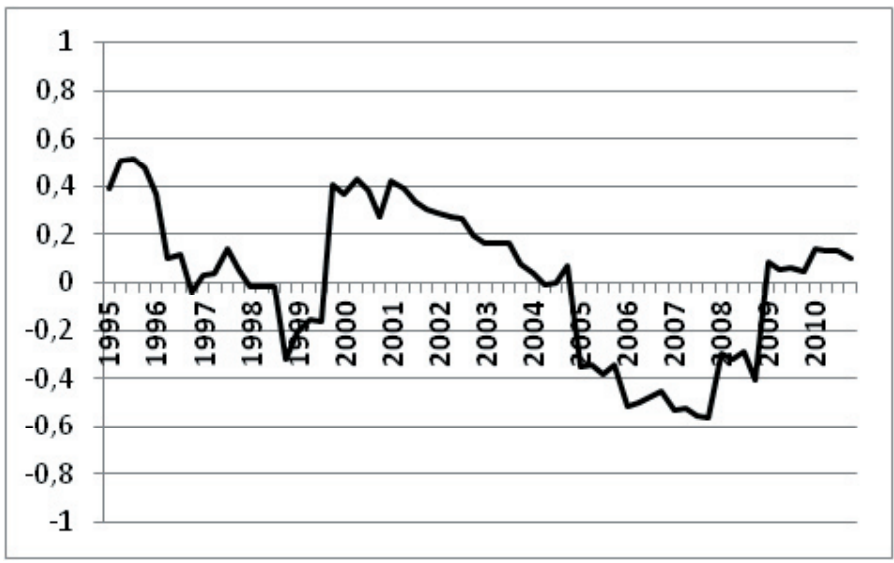

Source: Own calculation, based on data from the International Financial Statistics of the IMF.

moving correlations showing only small further changes. For the following analysis, we can therefore focus on the period up to early 2009. As mentioned before, Fidrmuc and Korhonen (2009: 7-9) have used a similar approach, with a smaller sample of countries, but including India as another potential source of 'autonomous' growth, and only using data from the fourth quarter of 2005 to the third quarter of 2008. Relating China and India to the US, Japan and Germany, they find no convincing overall correlation. Correlations with the US increased somewhat during the recent crisis ( 2008) somewhat less so with Germany, however. In conclusion, their results are compatible with ours.

As the general trend is still quite unclear, we turn to another, related approach. With the following regression analysis, one tries to statistically explain the GDP growth of single East Asian countries with that 
of OECD countries and of emerging economies. Compared to the correlation analysis outlined above, the GDP development of an individual country is now related to a whole group of economies. While this might also have been achieved with yet another correlation analysis, the quest is now for a consistent, statistically reliable trend. Searching for such a trend, it is meaningful to ask whether there are peculiarities for certain periods, namely for the Asian financial crisis and for the most recent global financial crisis. In a regression analysis, this question can be conveniently included by asking, if during such a period, a dummy variable turning ' 1 ' instead of ' 0 ' in all other cases has an identifiable, statistically reliable influence on the explained variable. Similar to Fidrmuc and Korhonen (2009: 9), we use the following equation for a panel regression:

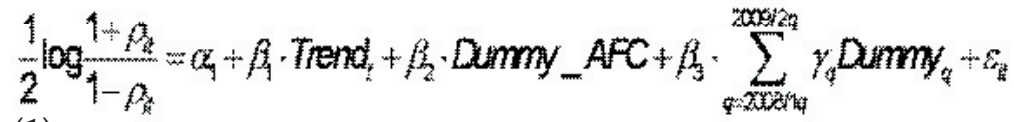

The dependent variable on the left hand side is a four-year moving correlation coefficient $\rho$ of de-trended real GDP of a certain economy i with selected countries; in our case, we apply this approach to three such countries 'i' in turn, namely China, Japan and South Korea. The countries that were selected for comparison are an OECD sample ${ }^{1}$ of 20 economies, as well as a group of seven emerging economies from East and Southeast Asia. We run the regressions for all countries (OECD sample plus emerging economies sample) as well as for the subsamples of developed (OECD) and regional (emerging) economies. The dummy variable for the Asian financial crisis (AFC) consists of the quarters 1997/3Q to 1998/4Q, while for the most recent global financial crisis we chose individual dummies for the quarters 2008/Q1 to 2009/Q2. The overall time-frame is 1995/1Q to 2009/2Q. Our approach is again inspired by Fidrmuc and Korhonen (2009), who investigate 19 OECD countries and six emerging economies with data up to the final quarter of 2008. We will report to what extent our somewhat wider and more recent regressions are compatible with their findings.

Here, we present results for three economies under investigation, namely China, Japan and South Korea. The detailed regression results can be found in Appendices 1 to 3. As for China, the data shows a weak coupling trend over the long term, that is, since 1995 (the trend variable is small and positive, namely 0.056 , and this result is highly reliable or statistically significant, denoted by the three stars after the value in the table of Appendix 1). Interestingly, this coupling is not stronger with 
emerging East and Southeast Asia than with OECD, as the trend values in all three columns (1) to (3) are almost identical and equally significant. During the Asian financial crisis of the 1990s, we find no significant trend (which differs from Fidrmuc and Korhonen; see the second row 'Dummy for Asian Financial Crisis' in Appendix 1, which does not contain any significant estimate), while we can confirm their finding of a positive coupling relationship for the recent global crisis, which even increases in early 2009 (see the highly significant estimates in the following rows, in the range of 0.1 to 0.3 in 2008 and more than 0.5 in early 2009). As for Japan (Appendix 2), generally speaking, it shows a low, but significant decoupling trend from emerging East and Southeast Asia, while there is no clear longer term tendency with respect to OECD. During the Asian financial crisis, Japan exhibited some decoupling from OECD, but during the recent financial crisis, some coupling: the algebraic sign for the significant Asian Financial Crisis estimates are negative, while they are mostly positive in 2008-2009. Results for relations with East and Southeast Asia during the recent crisis are mostly not very significant. Finally, South Korea (Appendix 3), like China, also has a weak positive trend with respect to all countries and to the region; this relationship is insignificant for the OECD sample, though. There is a somewhat stronger positive link (coupling) during the Asian crisis and during the latter part of the current crisis.

These two approaches by no means exhaust the possibilities of looking for the co-movement of business cycles. First, one finds simple modifications to the specifications made: for instance, changing the countries under study, changing the mode of calculating (moving) averages or which (dummy) variables to use in the regressions. Another option is to calculate averages for several countries, for instance looking at the correlation of all East Asian countries vis-à-vis the group of major Western economies (e.g., ADB 2007). Results may look 'smoother', but a lot of meaningful divergence may be hidden behind averaging. Second, there are more substantive modifications or extensions. For instance, Fidrmuc and Korhonen (2009) make use of so-called dynamic correlation analysis. This approach (Croux et al. 2001) is based on the idea that the usual concept of co-movement is too rough; the approach deals with the frequency under which variables co-move, possibly at the level of business cycle frequencies. While it is difficult to interpret the complex results properly, Fidrmuc and Korhonen (2009: 14) find evidence that the co-movement between Asia and the West has shifted to business cycle frequencies during the recent crisis, which is not in line with the 
secularity thesis of decoupling. Third, there are still other methods available to look at co-movement. For instance, the ADB (2007: 76) studies whether business cycles between Asia and the G3 (US, Japan, EU-25) can be understood to 'statistically cause' each other. The methodology is based on the so-called Granger causality, which looks at the movement of one variable in terms of it being statistically explained by another variable. The causing variable will precede the explained variable, but the lag period is not theoretically obvious. The ADB (2007) finds evidence that after the Asian financial crisis, but not before, G3 business cycles do indeed seem to Granger-cause Asian cycles, but not the other way round. This does not seem compatible with the secularity thesis of decoupling.

Summing up, while there are many different methodologies, it is hard to find convincing evidence for a secular decoupling of East Asia from the West. It is surprising, therefore, that the thesis has found so much interest. We will search for the reasons in the following section.

\section{Discursive Patterns}

If it is so difficult to make valid empirical statements about decoupling, if there is indeed not even a solid theoretical base to develop arguments from, why has the debate become so prominent during the mid-noughties?

One source of the mini-hype is the somewhat lofty analytical contributions of the financial sector. Talking about a decoupling of the East Asian (financial) markets could offer new and arguably imaginative investment ideas for clients and could thus help to distinguish one from competitors who were also looking for commission fees from potential investors. From this perspective, decoupling belongs to the same category of neologisms as BRICs (Brazil, Russia, India, China), a term that was meant to capture the investment opportunities offered by major emerging economies. Interestingly, Jim O'Neill, chief economist of Goldman Sachs, who invented the term BRICs and gained fame (and probably personal income) because of this, was considered the 'main cheerleader' of decoupling. ${ }^{2}$ Particularly in journalism, this background of the decoupling debate has been highlighted quite frequently. For instance, after the first incidents of a global cooling-down in late 2007, Dennis Moore of Thomson Financial News quite pointedly argued in an article entitled 'Decoupling theory looks dubious after global stocks plunge and Fed cuts rates', that 'Decoupling was the latest of the 
periodic "it's different this time" theories to sweep through the world's financial markets'. ${ }^{3}$ It is interesting to note that the term 'decoupling theory' is frequently used in publications, but as has been argued above, it is quite dubious whether there are any arguments that could safely be awarded the title 'theory'. The term 'decoupling debate' seems much more appropriate. We agree with Willett, Liang \& Zhang (2010), that the interest in decoupling issues hardly derives from careful analytical thinking, but is rather characterized by 'rapid swings in their popularity [that] are due largely to herding in popular mental models and shifts in short run correlations' (2010: 1).

However, we want to stress a second aspect here. Apart from the arena of financial journalism, policy circles have also shown a considerable interest in the term in recent years. It could serve as a concept to show the strength of East Asian economic dynamism and thus prepare the ground for arguments in favour of stronger regional integration. It is noteworthy that quite a number of the comparatively sophisticated studies on decoupling and its related issues have been published in the context of ADB or the Asian Development Bank Institute (for instance, Kawai \& Motonishi 2005; Rana 2006; ADB 2007; Kim et al. 2009). Actually, such studies lend the idea of decoupling a considerable degree of respectability, also by being quite separated from the somewhat flamboyant world of financial journalism, which is almost totally disregarded in such scholarly contributions.

It is certainly understandable that think-tanks make an effort to take up fashionable terms and use them to move public policy discussions in a certain direction. We want to concentrate on one link here, namely with respect to the ADB. In this regard, the leadership of personalities such as Haruhiko Kuroda, the president of ADB, or Masahiro Kawai, the dean of the ADB Institute in Tokyo, seems remarkable. It has often been mentioned that Japan, in particular, has encountered considerable problems with employing intellectual leadership to forward its agenda of promoting further institutional integration in Pacific Asia (Pascha 2002). We interpret efforts to support studies on decoupling as a means to overcome this hurdle. It is of course difficult to present conclusive evidence for such a background, but it is well known that circles close to the Asian faction of Japan's Ministry of Finance have for many years tried to promote a developmentalist and integration-oriented strategic concept for Pacific Asia (Lee 2008).

Such an effort to use certain theory-related (if not theory-based) concepts for policy goals is not without problems, however. This is true 
whenever positive analysis is utilized for normative ends. An example is the debate about the so-called flying geese pattern of economic development in East Asia. This approach was originally developed by a Japanese economist, Kaname Akamatsu, in the 1930s to discuss the catch-up process of industrial change and modernization of late-coming economies like Japan. Following reformulations by other Japanese economists (for a recent contribution, see Ozawa 2005), the concept came to be mainly about the catching-up product cycles of laggard economies, ranging from, along the time axis, imports to domestic production and exports, much later to be followed by a second import stage. Such cycles are related to the industry cycles of more advanced and of less advanced economies in a typical pattern: an old industry of an advanced economy is phased out and is taken over by the 'middle ranking' catch-up economy. While this country is gaining expertise and becoming a successful exporter, even less developed countries start to take over production in this industry, while the 'middle' country switches to more capital-, human capital- or technology-intensive industries. During this process, all countries involved can profit from this staggered pattern of moving into new industries. Should a less developed country move into a higher value-added industry 'too early', it forsakes the full advantages of the international distribution of labour; rather, it should wait for a suitable point in time, when a more advanced country moves out of some industry. The less developed country then moves into this void and is soon exporting upwards into the advanced economy, which has vacated this industry, and downwards, to countries that are still not able to introduce this industry. Summing up, such a pattern explains the staggered industrialization in the East Asian region, with Japan being first to introduce 'old' industries from the West, such as textiles during the first half of the twentieth century, later to be followed by the 'tiger' economies (South Korea, Taiwan), and even later by second-wave emerging economies in Southeast Asia or, most prominently by China.

The approach has been quite successful in explaining certain aspects of how the industrial development among a group of outward-oriented emerging economies has unfolded. However, there are two major problem areas. One is related to the status of the approach as a proto-theory, the other relates to its use for policy-making. First, the approach makes unconditioned predictions about how industries will develop, while important mechanisms are not satisfactorily covered. For instance, is it really necessary to enter a new industry through the import stage? 
What exactly are the assumptions about the options and limitations of entrepreneurs or international enterprises operating in such a terrain? Important properties such as the time dimension are not well defined; for instance, it is not specified how long certain phases are expected to last. Assumptions about technological advance are not well specified either. Is it possible to technologically leap-frog certain intermediate phases, for instance; if not, why not? While the approach may have been didactically helpful to understand basic features of earlier developments, it cannot be regarded as a workable theory to explain current patterns or predict future patterns (e.g., Bernard \& Ravenhill 1994; Kasahara 2004). Despite these theoretical weaknesses, the concept has been used in policy circles as an argument to favour a close coordination of regional industrial policies. According to the $\mathrm{V}$-shaped 'flying geese' pattern of staggered industry cycles, it would have been best for Asian latecomers to follow the Japanese lead goose and coordinate their policies with the leader, accepting specialization on and belated graduation from less advanced industries to profit most from regional distribution of labour. From a political economy perspective, some interested actors, certainly not all involved in contributing to the concept, misused the concept to promote the idea of a Japanese leadership. It is argued for instance, that circles close to the former Ministry of International Trade and Industry (MITI) of Japan had an interest in 'exporting' the Japanese concept of an activist industrial policy and in shaping the policy debate in East Asian cooperation schemes accordingly (see, for instance, Korhonen 1994; Hatch \& Yamamura 1996).

Comparing the fashionable debate about decoupling and the somewhat older popularity of the flying geese pattern, we feel that both concepts face the danger of being misused by interested actors in the debate of East Asian regional integration. This potential danger is based on common characteristics. First, they make assertions about a stronger regional integration than is supported by the current consensus among policy circles in the region. Second, both concepts are loosely defined and do not have a strong basis in well-supported economic theory, which allows them to move well beyond safe levels about empirical realities. Third, both can be related to established empirical economic methodologies, time series analysis of trade data in the case of the flying geese approach or business cycle co-variation analysis, for example, in the case of decoupling. Statements based on these concepts can thus potentially profit from the halo effect of empiricist jargon. This does not imply that there is no grain of salt in the concepts. Both deal with the 
peculiar economic dynamism of the East Asian region, and both can be interpreted as interactive models of political and economic exchange on a regional level. If such a successful interaction is in line with multilateral trends, it would lead to coupling; if not, one would notice aspects of decoupling.

Nevertheless, why is the debate about regional integration of East Asia so vulnerable to analytical hazards? It would go beyond the scope of this paper to argue that issues like this would not be able to occur or would be less likely in other policy arenas, like the regional integration debate in Europe or in totally unrelated (economic) policy arenas. Nevertheless, we see some properties of the regional integration debate on East Asia that seem to make it vulnerable. First, it is well known that it is difficult to set up institutional regional integration because of the public good properties involved. In the case of the EU, the devastating Second World War and the Cold War set conditions that convinced a first group of Western European economies to move closer together in the European Coal and Steel Community of 1951 and thus realized a seed crystal for further integration steps (e.g., Pascha 2005). In the case of East Asia, such a major reason and strong urgency to move beyond first mover disadvantages is not in sight. Thus, there is a clear incentive for intellectual leadership to 'artificially' strengthen the case for integration, seeking intellectual foundations wherever one can hopefully find them, possibly beyond the borderline of academically sound argument. Second, the public good problem of institutional integration could be overcome by strong hegemonic leadership or a coalition with a suitable agenda. In the case of Europe, this was fulfilled by the German-French rapprochement after the Second World War under US patronage. In the case of East Asia, there is no clear leadership in the region; one may even be tempted to speak of a scramble for leadership among China, Japan and, possibly, the US. Under such circumstances, arguments may also easily be bloated in order to achieve policy impact. Finally, it should also be stressed that the case for further institutional integration is by no means self-evident, particularly if one considers the different forms and contents such institutional integration might encompass. For instance, one can refer to the long debate whether trade arrangements in the region would rather be a stepping stone or a stumbling-block for multilateral welfare-enhancing trade agreements (Baldwin 2004) or whether East Asia can be considered to eventually approach the conditions for an optimal currency area (Kawai 2009). Under such circumstances, it is again conceivable that there are strong motives for interested parties 
to try to tilt the public debate in their favour and to bend empiricallybased arguments accordingly.

\section{Conclusions/Summary}

In this paper we looked at the decoupling debate from an economic and from a political economy perspective. In the economic analysis, the authors try to operationalize the term decoupling and to empirically estimate its development over the years. We have noticed that there is no well-established relationship of the concept of decoupling to economic theory, so it is quite open, though not arbitrary, what is understood by the term. For instance, there is no clear understanding whether financial or real economic phenomena are more relevant. Beyond the definition of relevant phenomena, the extent of decoupling is difficult to measure as it always involves comparisons across time and with other entities. Empirical methods can be quite sophisticated, and it is sometimes difficult to interpret their results consistently and congenially with a prescientific understanding of (de)coupling. Looking at various methods, we found little evidence to support a secular decoupling hypothesis, that is, the proposition that there is a long-term trend towards a decoupling of the East Asian region. Rather, we found evidence in favour of a cyclical relationship: decoupling during economic upturns and re-coupling during downturns.

Given this sobering result, we asked about the sources for the strong interest in the concept in recent years. One key factor is the activity of financial analysts, who are always on the lookout for attractive ideas to generate and canalize interest in new investment ideas. Second, some policy circles in the region have an interest in supporting calls for further regional integration with putative empirical evidence. The debate for regional integration is particularly prone to such argumentation because of the difficulties in finding suitable policies and executing them against the public action problem of creating public goods and the lack of a clear leadership in the region. The concept of (de)coupling and the older one of the flying geese pattern of economic development capture some interesting points about the peculiar political and economic exchange on the regional level. Nevertheless, we conclude that seemingly detached economic reasoning is often subject to over- and even misinterpretation and should be accompanied by more political economy-based reasoning, capturing the discursive patterns of the scholarly-cum-political debate. 
Werner Pascha is Deputy Director of the Institute of East Asian Studies and Professor in East Asian Economic Studies/Japan and Korea at the Mercator School of Management, Duisburg-Essen University in Germany (werner. pascha@uni-due.de).

Jihee Yoon is a doctoral candidate at the Mercator School of Management, Duisburg-Essen University, Germany, doing research on international trade (jihee.yoon@uni-due.de).

\section{NOTES}

1 Our OECD sample (developed countries group) consists of Australia, Austria, Belgium, Canada, Denmark, Finland, France, Germany, Iceland, Ireland, Italy, Japan, Luxembourg, Netherlands, Norway, Spain, Sweden, Switzerland, UK and US. Our seven emerging economies are China, Hong Kong, Indonesia, Korea, Malaysia, Singapore and Thailand.

2 D. Oakley, 'Decoupling gains brand new group of cheerleaders', Financial Times, 12 June 2009, p. 25.

3 D. Moore, 'Decoupling theory looks dubious after global stocks plunge and Fed cuts rates', AFXNews Ltd., 22 January 2008. Available from: http://www.forbes. com/feeds/afx/2008/01/22/afx4559340.html (accessed January 2011).

\section{REFERENCES}

Asia Development Bank (ADB) 2007. 'Uncoupling Asia: Myth and Reality'. In Asian Development Outlook, 66-81. Available from: http://www.adb.org/Documents/ Books/ADO/2007/ado2007.pdf (accessed December 2010).

Baldwin, R.E. 2004. Stepping stones or building blocs? Regional and multilateral integration. Prepared for the G-20 Workshop on 'Regional economic integration in a global

Framework', Beijing, 22-23 September 2004. Available from: http:/ / phase1.nccr-trade. org/images/stories/publications/Baldwin_SteppingStones.pdf.

Bernard, M. and J. Ravenhill 1994. 'Beyond product cycle and flying geese: regionalization, hierarchy, and the industrialization of East Asia'. World Politics, 47 (January): 171-209.

Croux, C., M. Forni and L. Reichlin 2001. 'A measure of comovement for economic indicators: theory and empirics'. Review of Economics and Statistics, 83: 232-241.

Fidrmuc, J. and I. Korhonen 2009. The Impact of the Global Financial Crisis on Business Cycles in Asian Emerging Economies, CESifo Working Paper, No. 2710, July. Munich: Center for Economic Studies, Ifo Institute.

Frankel, J.A. 1997. Regional trading blocs in the world economic system. Washington DC: Institute for International Economics.

Hatch, W. and K. Yamamura 1996. Asia in Japan's embrace: building a regional production alliance. Cambridge: Cambridge University Press.

International Monetary Fund (IMF). International Financial Statistics. Available from: http://elibrary-data.imf.org/ (accessed October 2011).

Kasahara, S. 2004. The Flying Geese Paradigm: A critical study of its application to East Asian regional development. UNCTAD Discussion Paper No.169. 
Kawai, M. 2009. 'Asian Monetary Integration: Lessons from Europe'. Paper presented at the conference 'Bridging the Gap between Economics and Area Studies: Economic Theory and the Diversity of Policies and Institutions', Blankensee-Colloquium 2009, Kremmen, mimeo.

Kawai, M. and T. Motonishi 2005. 'Macroeconomic Interdependence in East

Asia: Empirical Evidence and Issues'. In Asian Economic Cooperation and Integration: Progress, Prospects and Challenges, edited by Asian Development Bank, 213-268. Manila: Asian Development Bank.

Kim, S., J.-W. Lee and C.-Y. Park 2009. Emerging Asia: Decoupling or Recoupling. Asia Development Bank Working Paper Series on Regional Economic Integration, No. 31, June.

Korhonen, P. 1994. 'The Theory of the Flying Geese Pattern of Development and Its Interpretations'. Journal of Peace Research, 31(1): 93-108.

Krugman, P. 1994. 'Competitiveness: A Dangerous Obsession'. Foreign Affairs, 73 (March/April): 28-44.

Lee, Y.W. 2008. The Japanese Challenge to the American Neoliberal Order. Identity, Meaning, and Foreign Policy. Stanford: Stanford University Press.

Ozawa, T. 2005. Institutions, industrial upgrading, and economic performance in Japan. The 'Flying Geese' Paradigm of Catch-Up Growth. Cheltenham: Edward Elgar.

Pascha, W. 2002. 'Japan's Role in APEC: Wavering Or Leading from Behind?' In AsiaPacific Economic Cooperation (APEC). The First Decade, edited by J. Rüland, E. Manske and W. Draguhn, 153-183. London: Routledge/Curzon.

Pascha, W. 2005. 'The role of APEC in East Asian regional integration: A European perspective'. The Journal of East Asian Affairs, 19(2): 109-134.

Pula, G. and T.A. Peltonen 2009. Has Emerging Asia Decoupled? An Analysis of Production and Trade Linkages Using the Asian International Input-Output Table. European Central Bank Working Paper, No. 993, January.

Rana, P.B. 2006. 'Economic Integration in East Asia: Trends, Prospects, and a Possible Roadmap'. ADB Working Paper Series on Regional Economic Integration, No. 2. Manila: ADB.

Urata, S. 2004. 'A Shift from Market-led to Institution-led Regional Economic Integration in East Asia'. RIETI Discussion Paper Series, 04-E-012. Available from: http:/ / www. rieti.go.jp/jp/publications/dp/04e012.pdf (accessed December 2010).

Willett, T.D., P. Liang and N. Zhang 2010. 'Global Contagion and the Decoupling Debate', Unpublished manuscript of 26 April 2010, Available from: www.cgu.edu/ MSDocs/SPE/Decoupling_Draft_April26a_2010.doc (accessed December 2010). 
APPENDIX 1: China's Business Cycle Convergence

\begin{tabular}{|l|c|c|c|}
\hline \multirow{2}{*}{ Trend } & \multicolumn{3}{|c|}{ China } \\
\cline { 2 - 4 } & $(1)$ All & $(2)$ Developed & $(3)$ Developing \\
\hline Dummy for Asian Finance & $0.056^{* * *}$ & $0.056^{* * *}$ & $0.055^{* * *}$ \\
Crisis & $(0.008)$ & $(0.009)$ & $(0.015)$ \\
\hline \multirow{2}{*}{ Dummy for 2008/1Q } & $(0.003$ & -0.020 & 0.052 \\
& $0.101^{* *}$ & $(0.028)$ & $(0.060)$ \\
\hline \multirow{2}{*}{ Dummy for 2008/2Q } & $(0.042)$ & 0.078 & $0.168^{* * *}$ \\
& $0.120^{* * *}$ & $(0.052)$ & $(0.066)$ \\
\hline \multirow{2}{*}{ Dummy for 2008/3Q } & $(0.042)$ & $\left(0.054^{*}\right.$ & $0.194^{* * *}$ \\
& $0.189^{* * *}$ & $0.166^{* * *}$ & $(0.061)$ \\
\hline \multirow{2}{*}{ Dummy for 2008/4Q } & $(0.041)$ & $(0.051)$ & $0.254^{* * *}$ \\
& $0.235^{* * *}$ & $0.206^{* * *}$ & $(0.063)$ \\
\hline \multirow{2}{*}{ Dummy for 2009/1Q } & $(0.055)$ & $(0.068)$ & $0.316^{* * *}$ \\
& $0.558^{* * *}$ & $0.573^{* * *}$ & $(0.085)$ \\
\hline \multirow{2}{*}{ Dummy for 2009/2Q } & $(0.060)$ & $(0.072)$ & $(0.110)$ \\
\hline \multirow{2}{*}{ Constant } & $0.521^{* * *}$ & $0.527^{* * *}$ & $0.510^{* * *}$ \\
& $(0.060)$ & $(0.074)$ & $(0.109)$ \\
\hline No. of countries & $-0.019^{* * *}$ & -0.076 & 0.145 \\
No. of quarters & $(0.070)$ & $(0.072)$ & $(0.110)$ \\
\hline No. of observations & 27 & 20 & 7 \\
\hline
\end{tabular}

Notes:

1. Dependent variable is moving correlation (4 years) of de-trended real GDP with selected countries.

2. Quarterly dummy variables: 2008/1Q 2009/2Q

3. Asian finance crisis dummy variable: 1997/3Q 1998/4Q

4. ( ) represents Robust Standard Error.

5. ${ }^{*}, * *, * * *$ denotes significance at $10 \%, 5 \%$, and $1 \%$ level, respectively.

6. (1) represents China in relation to all developed and developing countries in the sample, (2) represents China with all developed (OECD) countries only, (3) represents China with all developing group countries only. 
APPENDIX 2: Japan's Business Cycle Convergence

\begin{tabular}{|l|c|c|c|}
\hline \multirow{2}{*}{ Trend } & \multicolumn{3}{|c|}{ Japan } \\
\cline { 2 - 4 } & $(1)$ All & $(2)$ Developed & $(3)$ Developing \\
\hline Dummy for Asian Finance & $-0.011^{*}$ & 0.002 & $-0.049^{* * *}$ \\
Crisis & $(0.006)$ & $(0.007)$ & 0.013 \\
\hline \multirow{2}{*}{ Dummy for 2008/1Q } & $(0.022)$ & $-0.222^{* * *}$ & 0.045 \\
& $-0.090^{* *}$ & $(0.022)$ & 0.044 \\
\hline \multirow{2}{*}{ Dummy for 2008/2Q } & $(0.045)$ & -0.028 & $-0.267^{* * *}$ \\
& -0.009 & $(0.048)$ & 0.054 \\
\hline \multirow{2}{*}{ Dummy for 2008/3Q } & $(0.048)$ & 0.070 & $-0.236^{* * *}$ \\
\hline \multirow{2}{*}{ Dummy for 2008/4Q } & 0.091 & $(0.052)$ & 0.038 \\
\hline \multirow{2}{*}{ Dummy for 2009/1Q } & $(0.058)$ & $0.226^{* * *}$ & $-0.294^{* * *}$ \\
& $0.241^{* * *}$ & $(0.055)$ & 0.053 \\
\hline \multirow{2}{*}{ Dummy for 2009/2Q } & $(0.068)$ & $0.379^{* * *}$ & $-0.159^{*}$ \\
& $0.377^{* * *}$ & $(0.078)$ & 0.083 \\
\hline Constant & $(0.062)$ & $0.517^{* * *}$ & -0.029 \\
& $0.333^{* * *}$ & $(0.071)$ & 0.103 \\
\hline No. of countries & $(0.065)$ & $\left(0.0799^{* * *}\right.$ & -0.030 \\
\hline No. of quarters & $0.141^{* * *}$ & $0.119^{*}$ & 0.100 \\
\hline No. of observations & $(0.051)$ & $(0.062)$ & $0.210^{* * *}$ \\
\hline
\end{tabular}

Notes:

1. Dependent variable is moving correlation (4 years) of de-trended real GDP with selected countries.

2. Quarterly dummy variables: $2008 / 1 Q \sim 2009 / 2 Q$

3. Asian finance crisis dummy variable: 1997/3Q 1998/4Q

4. ( ) represents Robust Standard Error.

5. * $, * *, * * *$ denotes significance at $10 \%, 5 \%$, and $1 \%$ level, respectively.

6. (1) represents Japan in relation to all developed and developing countries in the sample, (2) represents Japan with all developed (OECD) countries only, (3) represents Japan with all developing group countries only. 
APPENDIX 3: South Korea's Business Cycle Convergence

\begin{tabular}{|l|c|c|c|}
\hline \multirow{2}{*}{ Trend } & \multicolumn{3}{|c|}{ Korea } \\
\cline { 2 - 4 } & $(1)$ All & $(2)$ Developed & $(3)$ Developing \\
\hline Dummy for Asian Finance & $0.014^{* * *}$ & 0.011 & $0.025^{* *}$ \\
Crisis & $(0.006)$ & $(0.007)$ & $(0.011)$ \\
\hline \multirow{2}{*}{ Dummy for 2008/1Q } & $(0.017)$ & $0.063^{* * *}$ & 0.031 \\
& 0.019 & $(0.018)$ & $(0.038)$ \\
\hline \multirow{2}{*}{ Dummy for 2008/2Q } & $(0.035)$ & $(0.008$ & 0.096 \\
& -0.014 & -0.050 & $(0.067)$ \\
\hline \multirow{2}{*}{ Dummy for 2008/3Q } & $(0.034)$ & $(0.037)$ & 0.092 \\
& 0.031 & 0.000 & $0.063)$ \\
\hline \multirow{2}{*}{ Dummy for 2008/4Q } & $(0.033)$ & $(0.036)$ & $\left(0.120^{*}\right.$ \\
& $0.068^{*}$ & 0.035 & $0.165^{* *}$ \\
\hline \multirow{2}{*}{ Dummy for 2009/1Q } & $(0.038)$ & $(0.043)$ & $(0.072)$ \\
\hline \multirow{2}{*}{ Dummy for 2009/2Q } & $0.224^{* * *}$ & $0.214^{* * *}$ & $0.255^{* * *}$ \\
& $(0.052)$ & $(0.063)$ & $(0.090)$ \\
\hline \multirow{2}{*}{ Constant } & $0.165^{* * *}$ & $0.131^{* *}$ & $0.258^{* * *}$ \\
\hline No. of countries & $(0.052)$ & $(0.064)$ & $(0.090)$ \\
\hline No. of quarters & $0.270^{* * *}$ & $0.253^{* * *}$ & $0.317^{* * *}$ \\
\hline No. of observations & $(0.077)$ & $(0.087)$ & $(0.112)$ \\
\hline Notes & 27 & 20 & 7 \\
\hline
\end{tabular}

Notes:

1. Dependent variable is moving correlation (4 years) of de-trended real GDP with selected countries.

2. Quarterly dummy variables: 2008/1Q 2009/2Q

3. Asian finance crisis dummy variable: 1997/3Q 1998/4Q

4. ( ) represents Robust Standard Error.

5. ${ }^{*}, * *, * * *$ denotes significance at $10 \%, 5 \%$, and $1 \%$ level, respectively.

6. (1) represents (South) Korea in relation to all developed and developing countries in the sample, (2) represents Korea with all developed (OECD) countries only, (3) represents Korea with all developing group countries only. 